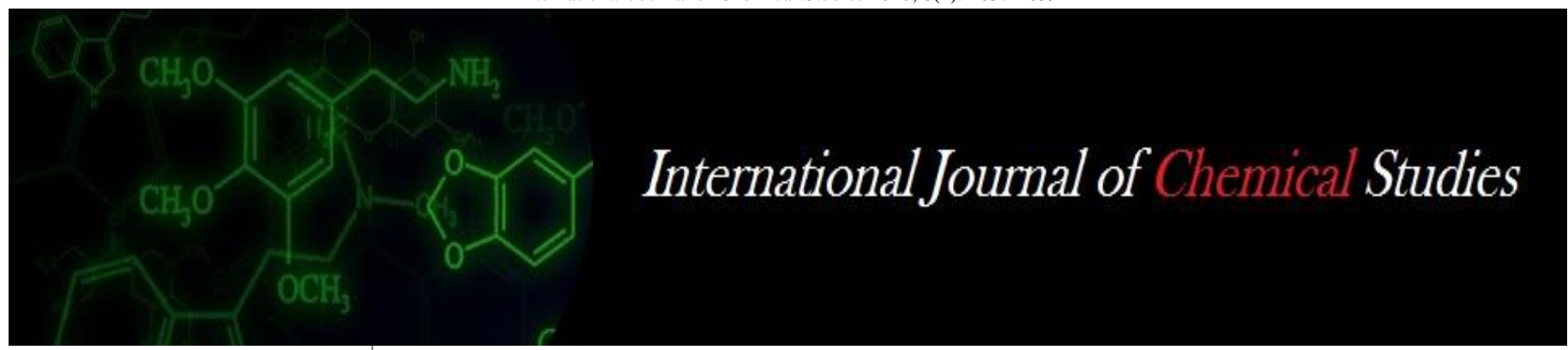

P-ISSN: 2349-8528

E-ISSN: 2321-4902

www.chemijournal.com

IJCS 2020; 8(1): 2637-2639

(C) 2020 IJCS

Received: 22-11-2019

Accepted: 24-12-2019

\section{K Geetha}

Department of Social Sciences,

Anbil Dharmalingam

Agricultural College and

Research Institute,

Tamil Nadu Agricultural

University, Tiruchirappalli,

Tamil Nadu, India

\section{Ilamaran}

Department of Food Science and

Nutrition, Community Science

and Research Institute,

Tamil Nadu Agricultural

University, Madurai, Tamil

Nadu, India

D Periyar Ramasamy

Department of Social Sciences,

Anbil Dharmalingam

Agricultural College and

Research Institute,

Tamil Nadu Agricultural

University, Tiruchirappalli,

Tamil Nadu, India

\section{E Abdullah}

Department of Social Sciences,

Anbil Dharmalingam

Agricultural College and

Research Institute,

Tamil Nadu Agricultural

University, Tiruchirappalli,

Tamil Nadu, India
Corresponding Author:

K Geetha

Department of Social Sciences,

Anbil Dharmalingam

Agricultural College and

Research Institute,

Tamil Nadu Agricultural

University, Tiruchirappalli,

Tamil Nadu, India

\section{Studies on optimize the process for development of millet based chocofills}

\author{
K Geetha, M Ilamaran, D Periyar Ramasamy and E Abdullah
}

DOI: https://doi.org/10.22271/chemi.2020.v8.i1an.8670

\begin{abstract}
The chocofills were formulated by different proportion of wheat flour and millet flours with the ratio of 60:40 $\left(\mathrm{T}_{1}\right)$, 40:60 $\left(\mathrm{T}_{2}\right)$ and 20:80 $\left(\mathrm{T}_{3}\right)$ respectively and compared with control $\left(\mathrm{T}_{0}\right)$. The chemical, functional and sensory properties of chocofills prepared from wheat and millets were evaluated. Nutritional quality of millet based choco fills was found to be higher than the control, which contain high fibre, calcium and iron. The sensory evaluation of the millet based choco fills illustrated that the according to overall acceptability mean score of sample (T3) scored maximum followed by other treatments and control.
\end{abstract}

Keywords: Studies, optimize, process, development, millet based chocofills

\section{Introduction}

In recent years in India, bakery products have become popular among different cross sections of the population due to an increased demand for convenience foods. Bread and cookies accounting for $80 \%$ of total bakery products produced in the country (Davidson, 2016) ${ }^{[3]}$. The demand of bakery products is increasing at the rate of $10.07 \%$ per annum. India is a developing country with large segment of population depending on wheat as staple foods and $25 \%$ of wheat is used in the preparation of baked foods. Baked products are considered as an excellent vehicle for fortification, value addition and feeding at mass scale. Baked products can be made a good source of dietary fiber in the total food consumption as they are consumed and relished by all age groups (Meenu Aggarwal et al., 2018) ${ }^{[4]}$. Baked products are gaining popularity because of their availability, ready-to-eat convenience and reasonably good shelf life. Cookies are ideal for nutrient availability, palatability, compactness and convenience (Chappalwar, 2013) ${ }^{[2]}$. It have been man's food since long time as it consumed across all age groups because of its ready to eat type of snack item. Cookie is a snack item. It originally contains refined flour, sugar, butter. A cookie made from refined wheat flour only may not be able to provide all the nutrition. As health is a major concern, in our day-to-day life, nutritious and health beneficial products are on high demand. Therefore, it is important to develop nutritionally enhanced products by utilizing under utilized crops (Millets). Keeping this in mind, a new innovative idea of making a snack item by incorporating millets in the choco fills, which can be a good vehicle to deliver whole grains, total dietary fibre in the diet and it may be a healthier snack option than the traditional cookies.

\section{Methodology}

All the ingredients such as millets, whole wheat flour,sugar, chocolate powder, butter or oil, baking powder/baking soda and skim milk were purchased from local market Tiruchirappalli. The standard procedure was adopted for preparing millets based choco fills by using millet flour (Ragi, Sorghum, Cumbu, Thenai, Samai, Kudhiraivali) along with wheat flour at the ratio of 40:60 (T1), 60: 40 (T2) and 20:80 (T3). The millet based choco fills were compared with the control (without millets flour). The sensory characteristics of the product prepared were evaluated by untrained judges by adopting 1-9 point hedonic scale. Based on the evaluation result the sample T3 was highly acceptable.

Chocofills was formulated and standardised with composite millet flour (Ragi, sorghum, bajra, Thenai, Samai and Barnyard) in combination with wheat flour at three different levels [as 40:60 (T1), 60:40 (T2) and 20:80 (T3)]. The chocofills were prepared with both 
millet and wheat flour for which the wheat flour based chocofills was considered as control.

Composite millet flour and wheat flour were taken as 40:60, 60:40 and 20:80 combinations. For all the three combinations vanaspathi, milk solids, power sugar flavouring components (vanilla), and water was added and then made into dough. The dough was rolled and cut into round shaped pieces. Place a chocolate in between the two round shaped pieces of dough and bake $\mathrm{t} 180{ }^{\circ} \mathrm{C}$ for 12 minutes.

\section{Functional Quality}

The samples were analysed for their functional quality such as diameter, thickness, weight and yield by the standard procedure.

\section{Chemical Analysis}

The chemical components such as moisture, energy, protein, fat, fibre, calcium, iron content of the sample was analysed as per the procedure given in AOAC $2000^{[1]}$.

\section{Organoleptic Evaluation}

The prepared millet based chocofills were evaluated organoleptically for various quality attributes such as colour, texture, flavour, taste and overall acceptability, by a panel of ten untrained judges using 9 point hedonic scale as per the procedure given by Watts et al. (1989) ${ }^{[5]}$. The acceptability of the developed products was assessed with different quality parameters viz., colour and appearance, flavour, texture, taste and overall acceptability.

\section{Consumer Acceptability}

Based on the sensory evaluation, the sample (T3) were selected for the consumer preference test. The consumer preference test was conducted at the Anbil Dharmalingham Agricultural College and Research Institute, Tiruchirappalli with staff and students. The sample (T3) and control were given to the subjects to evaluate the products with the help of the score card. The average of the consumer preference score was calculated for each sample, for each attribute. The consumer preference for each attribute of each sample was expressed in percentage.

\section{Results and Discussion}

The Choco fills were prepared by replacing refined wheat flour by minor millet flour. The chemical composition, functional qualities and consumer preference of the Choco fills incorporated with minor millets were analysed and discussed.

Table 1: Chemical composition of Choco fills incorporated with minor millets

\begin{tabular}{|c|c|c|c|}
\hline Sl. No & Chemical Composition & Control & T3 \\
\hline 1. & Moisture $(\mathrm{g} / 100 \mathrm{~g})$ & 3.5 & 4.3 \\
\hline 2. & Energy $(\mathrm{Cal} / 100 \mathrm{~g})$ & 856.0 & 867.04 \\
\hline 3. & Protein $(\mathrm{g} / 100 \mathrm{~g})$ & 10.32 & 10.06 \\
\hline 4. & Fat $(\mathrm{g} / 100 \mathrm{~g})$ & 50.00 & 52.06 \\
\hline 5. & Fibre $(\mathrm{g} / 100 \mathrm{~g})$ & 2.46 & 7.83 \\
\hline 6. & calcium $(\mathrm{g} / 100 \mathrm{~g})$ & 5.43 & 64.54 \\
\hline 7. & Iron $(\mathrm{mg} / 100 \mathrm{~g})$ & 0.28 & 5.05 \\
\hline
\end{tabular}

Table 2: Functional properties of millet based choco fills

\begin{tabular}{|c|c|c|}
\hline Properties & Control & T3 \\
\hline Diameter & 5.8 & 5.3 \\
\hline Thickness & 1 & .9 \\
\hline Weight & 45 & 42 \\
\hline
\end{tabular}

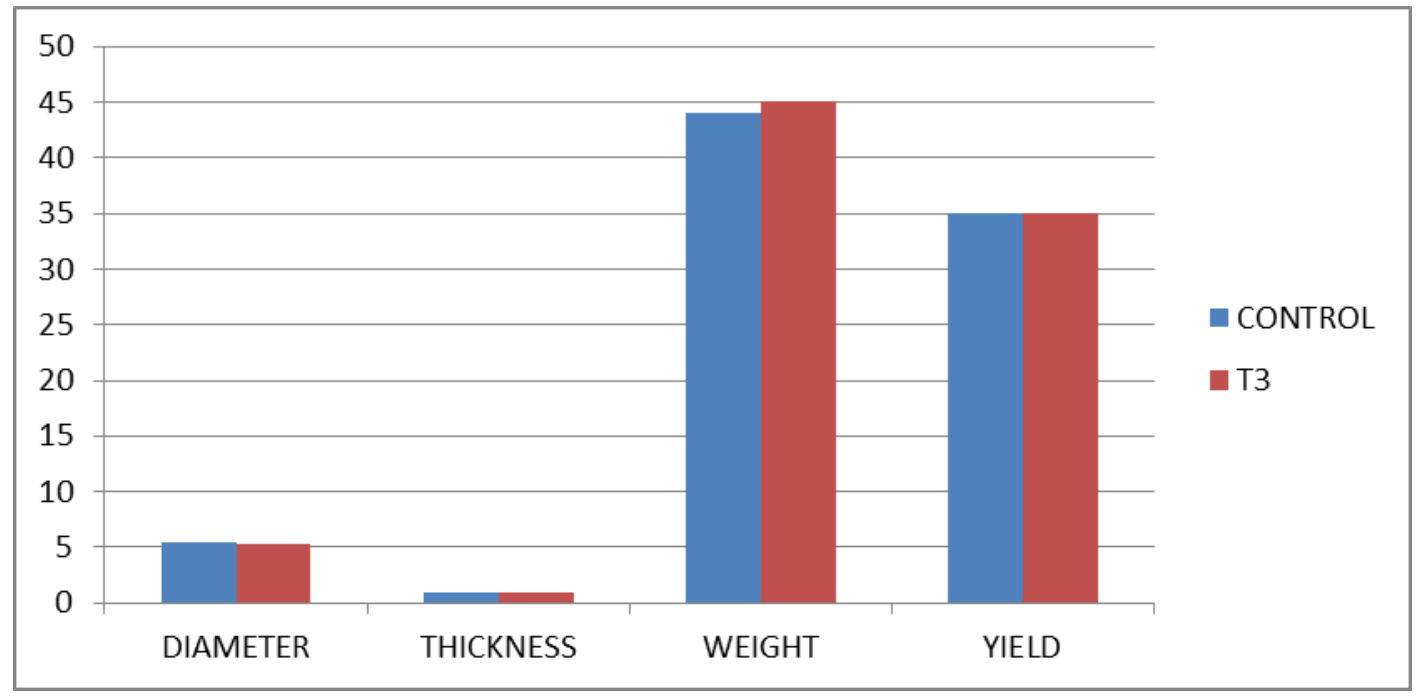

Fig 1: Functional properties of Choco fill 


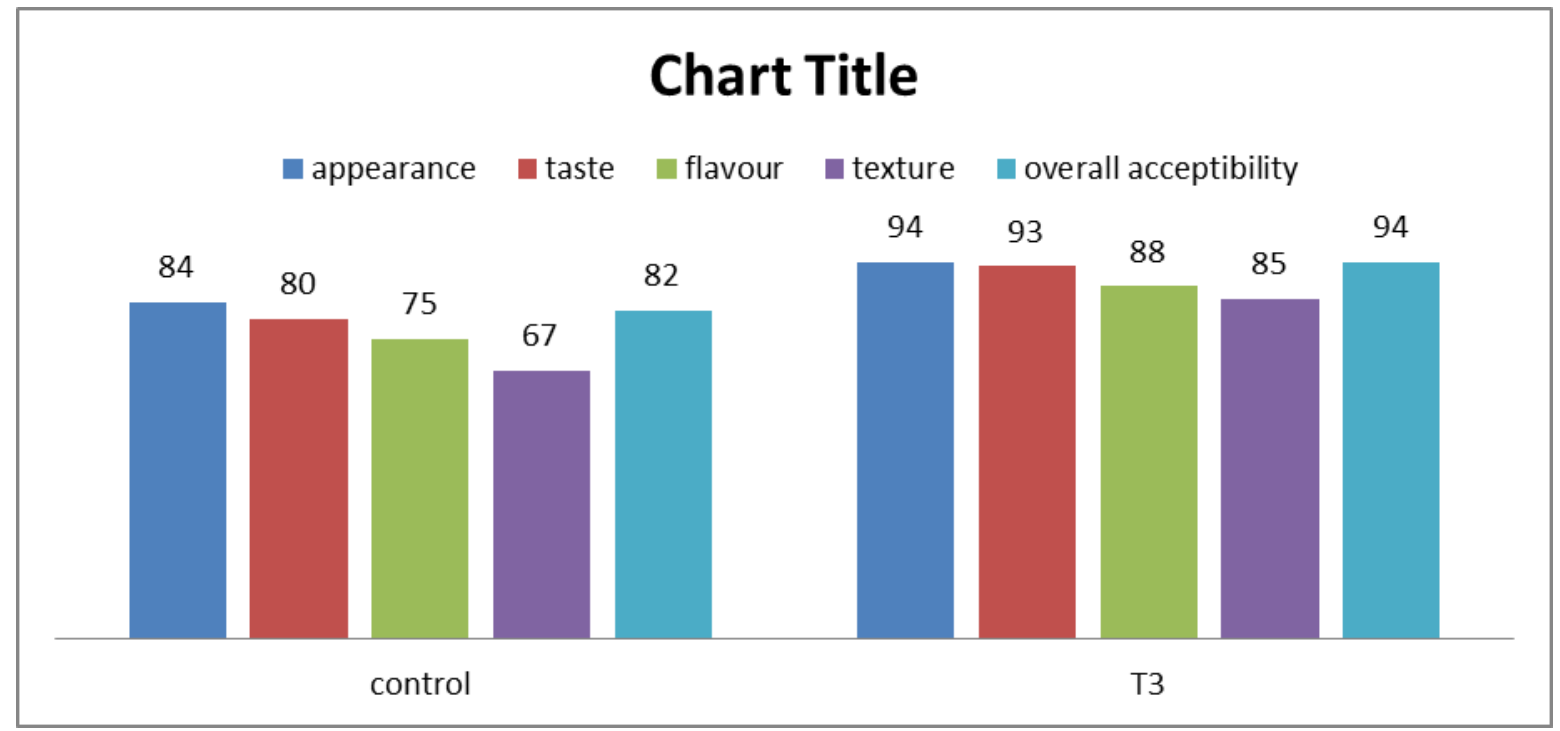

Fig 2: Organoleptic characteristic of the millet based Choco fills

Table 3: Consumer preference of the millet based choco fills

\begin{tabular}{|c|c|c|}
\hline Properties & Control (\%) & T3(\%) \\
\hline Appearance & 84.1 & 93.6 \\
\hline Taste & 80.1 & 92.8 \\
\hline Flavor & 74.6 & 88.09 \\
\hline Texture & 66.6 & 84.9 \\
\hline Over all acceptability & 81.7 & 93.6 \\
\hline
\end{tabular}

Chemical compositions of Choco fills incorporated with minor millets

The chemical composition of Choco fills incorporated with minor millets is presented in the table 1.The result indicates that fat, and fibre of the Choco fills incorporated with minor millets (T3) $(52.06 \mathrm{~g} / 100 \mathrm{~g}, 7.82 \mathrm{~g} / 100 \mathrm{~g}$,) was found to be slightly higher than the control $(50 \mathrm{~g} / 100 \mathrm{~g}, 2.46 \mathrm{~g} / 100 \mathrm{~g}$,).the calcium and iron content of Choco fills incorporated with minor millets (T3) $(64.54 \mathrm{~g} / 100 \mathrm{~g}, 5.05 \mathrm{mg} / 100 \mathrm{~g})$ was found to be higher than the control $(5.43 \mathrm{~g} / 100 \mathrm{~g}, 0.28 \mathrm{mg} / 100 \mathrm{~g})$ respectively.

Functional properties of Choco fills incorporated with minor millets

Choco fills incorporated with minor millets was analysed for the functional properties and the data obtained were presented in the table 2 and fig 1.The data revealed that diameter, thickness, weight of the millet based choco fills Choco fills (T3) was slightly lower than the control sample.

Organoleptic characteristic of the millet based Choco fills Result of organoleptic characteristic of the Choco fills incorporated with minor millets is presented in the fig 2.The data presented in the figure showed that the millet based choco fills (T3) secured higher score for all attributes such as appearance, colour, flavour, texture and overall acceptability than the control sample.

\section{Consumer preference of the millet based choco fills}

The average of the consumer preference score was calculated each attributes and percent mean score value for each sample were given in Table 3.The results of the table revealed that the sample (T3) was highly acceptable and secured the score of 93.6\% for the overall acceptability when compared with control $(81.7 \%)$.

\section{Summary and Conclusion}

Nutritional quality of millet based choco fills was found to be higher than the control, which contain high fibre, calcium and iron. The organoleptic evaluation of T3 sample was found to be highly acceptable than the control. Consumer preference test showed that T3 was highly acceptable. As the product prepared from millet based choco fills contain high carbohydrate \& dietary fibre can be recommended for normal persons and children.

\section{Reference}

1. AOAC. Official Methods of Analysis of A.O.A.C. International. Published by A.O.A.C, 2000. Virginia, USA, 2000.

2. Chappalwar VM, Dayan, Peter, Bobde H John, Steffi M. Quality characteristics of cookies prepared from oats and finger millet based composite flour. IRACSTEngineering Sci. \& Technol.: An Internat. J (ESTIJ). 2013; 3(4):677-683.

3. Davidson I. Biscuit Baking Technology: Processing and Engineering Manual. 2nd ed. Academic Press: Elsevier, 2016, 1-34.

4. Meenu Aggarwal, Dipti Sharma, Shivani. Development Of Multigrain Fibrous Gluten Free Millet Cookies, Plant Archives Vol. 18, Special Issue (ICAAAS-2018), P.NO., 2018, 232-236.

5. Watts BM, Yelimaki GL, Jeferry LE, Elias LG. Basic sensory methods for food evaluation International Development Research Centre, Canada, 1989. 